\title{
The Application of Alternative Techniques for Cooling, Flushing and Lubrication to Improve Efficiency of Machining Processes
}

\author{
Mario DRAGIČEVIĆ
}

\begin{abstract}
This paper represents a chronological view of the application and effectiveness of different alternative techniques for cooling, flushing and lubrication during different procedures of machining process. Based on the results of the literature review the merger of two alternative techniques, cooling with cold compressed air by using a vortex tube in combination with minimum quantity lubrication creates the possibility of improving the efficiency of machining processes with the fulfilling of the requirements of sustainability. Considering the fact that during the analysis of the literature research the effects of minimum quantity lubrication techniques on ecological and economic dimensions of sustainability are not completely presented, and that the application of the technique of compressed cold air in combination with minimum quantity lubrication is not fully investigated, there is a possibility for additional research based on which the possibility of increasing the efficiency of machining with a combination of the two techniques would be researched.
\end{abstract}

Keywords: alternative types of cooling; cooling with cold compressed air; dry machining; green manufacturing; minimum quantity lubrication; sustainable manufacturing

\section{INTRODUCTION}

In today's manufacturing industry, increasing attention is paid to the negative impacts that are damaging the social, health and economic picture of society caused by machining processes. Sustainable manufacturing involves the use of alternative techniques for cooling, flushing and lubrication which greatly affect all segments of machining processes like the social, economic and environmental. The concept of sustainable manufacturing appeared at the United Nations Conference on Environment and Development (UNCED) in 1992 and represents one of the main components of sustainable development. Achieving sustainable development will require changes in machining processes, in the type and quantity of resources used, in the treatment of waste, in the control of emissions of carbon dioxide $\left(\mathrm{CO}_{2}\right)$, and in the products produced [1].

Green manufacturing (GM) is a basis of sustainable development strategy in machining industry [2]. GM represents the most effective guidelines on the basis of which we should respect the laws and regulations with a goal to switching to sustainable manufacturing.

The main goal of machining process besides better productivity and efficiency is to get a high quality products. In addition to the cutting parameters of machining process cutting fluids (CFs) have a major contribution to the quality of the final products and tool life. The application of CFs in reducing cutting temperatures directly affects the decrease of tool wear and workpiece deformation, and increases the quality of finish products. During machining processes CFs enable satisfactorily the cooling and lubrication of cutting zone, and flushing chips away.

In recent years, it is widely known that the application of CFs creates several health and environmental problems [3]. The main goal of GM strategy is to unify all the problems from manufacturing processes and minimize all negative social, economic and environmental impacts during a product life cycle. In the conventional application of CFs, the chips produced are wet. They have to be dried before recycling, which incurs additional cost. The costs of conventional CFs supply will be increasingly higher due to the stricter enforcement of new health regulations and standards.
Today's manufacturing industry uses more than 2.4 billion liters of different CFs [4]. The United States' (US) utilization of CFs is estimated at 100 million gallons annually and the current worldwide consumption is about 640 million gallons annually. It is estimated that $52 \%$ is used for machining processes and $31 \%$ is applied to shaping processes [5]. The estimated annual usage of CFs by European Union (EU) is around 320,000 tones, out of which $66 \%$ is disposed after usage.

In early 1960s, scientists have begun to warn manufacturers about the negative impacts of CFs on the environment and health of workers. National Occupational Exposure Survey (NOES) estimated that 1.2 million workers are potentially exposed to the hazardous and harmful effects of CFs [6].

Global research started in the early 1990 s to investigate technologies to reduce the manufacturing costs associated with conventional CFs methods [7]. The costs for purchase, care and disposal of CFs are two times higher than machining costs and can represent between $7 \%$ and $17 \%$ of the total manufacturing costs compared to only $4 \%$ for cutting tools [8]. In the case of machining difficult to cut materials those costs reach up to $20 \%$ and $30 \%$ of the total manufacturing costs [9]. Recycling rates of CFs worldwide have been very low $[10,11,12]$.

In 2006. the EU adopted a famous REACH regulation about Registration, Evaluation, Authorisation and Restriction of Chemicals connected with problems of large amounts of not disposed CFs [13]. The REACH regulation includes all types of CFs and all phases, from production to the final disposal. Due to the reduction of negative impacts and implementation of environmental laws, the industry is forced to reduce the use of CFs. However, in some machining processes cutting fluids are necessary in order to obtain a good result due to the high amount of heat generated during machining.

Different alternative types for cooling, flushing and lubricating such as minimum quantity lubrication (MQL), cooling with compressed cold air and their possible combinations can help build GM strategy, reducing costs associated with coolants, promote job satisfaction among workers and raise the image of the company. 


\section{DRY MACHINING}

Dry machining is classified as environmentally friendly technique, which is successfully applied in many of the machining processes. The advantages of dry machining include no environmental pollution, reducing disposal and cleaning costs, no danger to health of workers [14]. The elimination of CFs involves the loss of their positive effects, such as cooling, lubrication and chip flushing. In the dry machining process, very high temperatures in the cutting zone accelerate tool wear. Development of production in terms of transition to dry machining supports the development of new cutting tools. Good resistance to thermal shock is an important characteristic of a suitable material. Materials for making tools can be classified into high speed steels (HSS), cemented carbides, cermets, ceramics like aluminum oxide or silicon nitride ceramics, cubic boron nitrides $(\mathrm{CBN})$ and diamond-polycrystalline diamond (PCD), Fig. 1 [15].

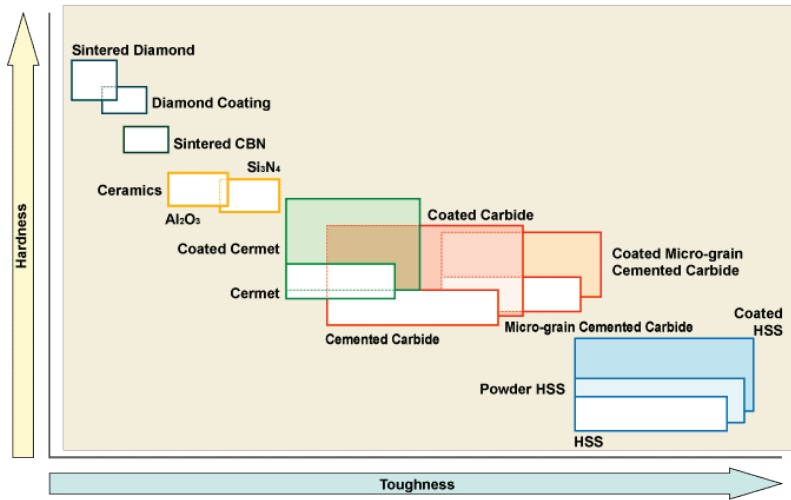

Figure 1 Mechanical properties for different types of tool materials [15]

Nowadays great advances can be seen in the field of coating technology, and also the interest for it in the market tools. Coatings have a tendency and possibility to replace CFs. Coatings for dry machining should decrease friction and temperature in the contact zone and enable high wear resistance at high temperatures [16]. Coatings enable to reduce different mechanisms of tool wear by forming a protective barrier between the cutting tool and workpiece.

The lubricating function of coatings in dry machining can be replaced with the soft coatings or so-called selflubricating coatings. Typical types of self-lubricating coatings are molybdenum disulfide $\left(\mathrm{MoS}_{2}\right)$ or tungsten carbide/carbon (WC/C). Self-lubricating coatings improve the behavior of cutting tool and also reduce the friction between the cutting tool and the workpiece. As a result of that, the cutting forces and heat generated during machining can be reduced [17].

Dry machining of AISI 316 stainless steel shows good results compared to machining with conventional CFs. [18, 19]. However dry machining of soft materials induces built-up-edge (BUE) and that has a huge impact on the surface quality of the workpiece and tool life during machining [20].

Advanced cutting tool materials and tool coatings are necessary during dry machining but they are very expensive and increase the total machining costs. In addition, another step towards an alternative solution in terms of GM and improving the quality of the finished products is to use the MQL technique.

\section{MINIMUM QUANTITY LUBRICATION MACHINING}

The concept of MQL technique includes the use of minimum amount of cutting [21]. Classification of different cooling and lubrication types and their volume of application are shown in Tab. 1 [22].

Table 1 Classification of different colling and lubrication types [22]

\begin{tabular}{|c|c|c|}
\hline Lubrication type & Content & Used volume \\
\hline $\begin{array}{c}\text { Wet machining } \\
\text { (using CFs coolant) }\end{array}$ & $\begin{array}{c}\text { Flooding supply, full } \\
\text { jet lubrication }\end{array}$ & $10 \mathrm{l} / \mathrm{min}$ to $100 \mathrm{l} / \mathrm{min}$ \\
\hline \multirow{5}{*}{ Reduced lubrication } & $\begin{array}{c}\text { Minimum quantity } \\
\text { lubrication (MQL) }\end{array}$ & $50 \mathrm{ml} / \mathrm{h}$ up to $1-21 / \mathrm{h}$ \\
\cline { 2 - 4 } & $\begin{array}{c}\text { Minimum quantity } \\
\text { cooling lubrication } \\
\text { (German abbrev: } \\
\text { MMKS) }\end{array}$ & $<50 \mathrm{ml} / \mathrm{h}$ \\
\hline Without lubrication & Dry machining & Without \\
\hline
\end{tabular}

During machining MQL coolant is delivered to the cutting zone as a fluid in the form of an aerosol. The aerosol presents small droplets of oil in the stream of high pressure air. Small amount of air-oil mixture used in MQL enables a strong temperature reduction effect from both cooling and lubrication what can effectively reduce cutting forces, tool wear and surface roughness during machining. Sharma et al. [23] confirmed that the rate of average principal flank wear is decreased in turning process by using MQL. Treurnicht and et al. [24] reported that the MQL technique can be successfully used in drilling operations of aluminum-silicon alloys, which is almost impossible with dry machining. Sundara and Rajendran [25] have investigated the influence of cutting parameters on surface roughness and optimum machining conditions for better surface quality during milling of $\mathrm{Al} \mathrm{6063.} \mathrm{The} \mathrm{results}$ indicated that MQL technique is a better choice compared to conventional CFs.

Application of MQL lubricant to the cutting zone can be possible in two different ways. The first one is external in the case when the lubricant is applied from outside as an aerosol using compressed air. Another possibility is internal lubrication through the rotating machine tool spindle and the inner channels of the tool, Fig. 2 [26].
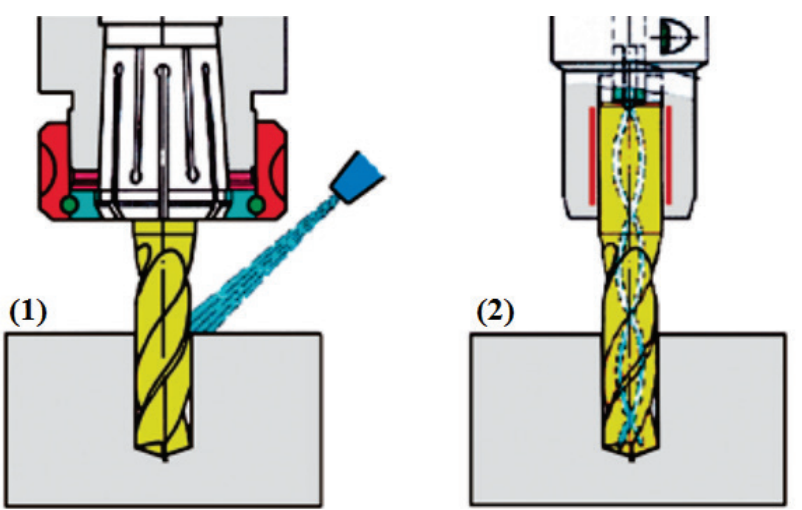

Figure 2 Application of MQL lubricant, 1 - external, 2 - internal [26]

Machining processes like milling, turning or drilling, can be easily implemented with external MQL. The internal MQL systems enable successful aerosol delivery to the cutting zone through the cutting tool. This makes it possible to drill very deep holes and use very high cutting speeds [26]. Zeilmann and Weingaertner [27] have stated that during drilling of Ti-6Al-4V internal MQL system 
gave the lower cutting temperatures than external MQL system. Heisel Uwe et al. [28] in their study confirmed that MQL systems in machining with geometrically defined cutting edges can be successfully implemented. Shahrom et al. [29] reported that MQL method gave better surface roughness than conventional CFs during milling process.

Very important parameter during MQL machining is the type of cutting fluids/oils. Due to their low consumption, the cutting fluids should be biodegradable and chemically stable during disposal. A small quantity of vegetable oil, ester oil, or equivalent synthetic fluid is preferable in MQL because of their superior lubrication at high pressure [30]. Nurul et al. [31] studied the performance of four vegetable oils, palm, sesame, olive and coconut, in MQL drilling of AISI 316 stainless steel using HSS drill tool. The authors point out that coconut oil is the best choice in terms of achieving better surface roughness and surface integrity. Tazehkandi et al. [32] showed that biodegradable vegetable oil can increase productivity of machining and reduce the costs of machining in turning of Inconel 706. Sharma and Sidhu [33] carried out a study of turning of AISI D2 steel under dry machining and machining with vegetable oil with MQL technique. It was observed that machining under MQL technique produced better surface roughness compared to dry condition. Khan et al. [34] confirmed that the effects of MQL during turning of AISI 9310 alloy steel by using vegetable oil were very successful in reducing the cutting temperature compared to conventional CFs. Liao et al. [35] have indicated that MQL method allows better surface roughness in higher cutting speed compared to conventional CFS and dry machining.

According to the previous studies, the MQL method can be an alternative to flood cooling especially in high speed milling. However, there is a need to develop its performance to machine hard to cut materials. For this reason, nanofluids have been produced by adding nanoparticles of metals, oxides, carbides, nitrides, or nanotubes such as carbon nanotube, Titanium Dioxide $\left(\mathrm{TiO}_{2}\right)$, Aluminum Oxide $\left(\mathrm{Al}_{2} \mathrm{O}_{3}\right), \mathrm{MoS}_{2}$, and diamond to the cutting fluids. These nanoadditives have a huge impact on improving the performance of MQL method. They can successfully improve the thermal conductivity and lubrication effect of the cutting fluids [36].

Subhash et al. [37] studied the effect of MQL and nanofluids on the machinability characteristics of Nicrofer C263 in turning with different conditions: dry, MQL and MQL in combination with $\mathrm{Al}_{2} \mathrm{O}_{3}$ nanoparticles. It was found that the use of combination of nanofluids and MQL gives better surface finish with good temperature dissipation in cutting zone when compared with other conditions.

It is important to note that a very significant role during delivery of nanoparticles to the cutting zone beside concentration in weight percent $(\mathrm{wt} \%)$ of nanoparticles has the value of pressure and angle of nozzles. Rahmati et al. [38] investigated the optimum $\mathrm{MoS}_{2}$ nanolubrication parameters in Al 6061-T6 milling process. The experimental results confirmed that the minimum cutting temperature and surface roughness are achieved with 0.5 wt. $\%$ and that cutting force can be minimized by applying $1 \mathrm{wt} . \% \mathrm{MoS}_{2}$ nanoparticle concentration in the mineral oil. Sayuti et al. [39] studied the optimum $\mathrm{SiO}_{2}$ nanolubrication parameters in milling of Al 6061-T6. These parameters include nanolubricant concentration, nozzle angle and air pressure. The results show that excellent properties of $\mathrm{SiO}_{2}$ nanoparticle can be a new effective alternative to achieve correct lubrication conditions for the lowest cutting force, cutting temperature and surface roughness. Rahmati et al. [40] provided an overview of the results of surface roughness using different amounts of nanoparticles $\mathrm{MoS}_{2}$ during milling Al 6061-T6 alloy. During machining delivery pressure of oil was $20 \mathrm{MPa}$ with a delivery rate of $30 \mathrm{ml} / \mathrm{min}$. The air pressure and nozzle orientation were 4 bars and $60{ }^{\circ} \mathrm{C}$. Results confirmed that the lowest surface roughness was obtained at $0.5 \mathrm{wt} \% \mathrm{MoS}_{2}$ nanoparticle concentration, Fig. 3.

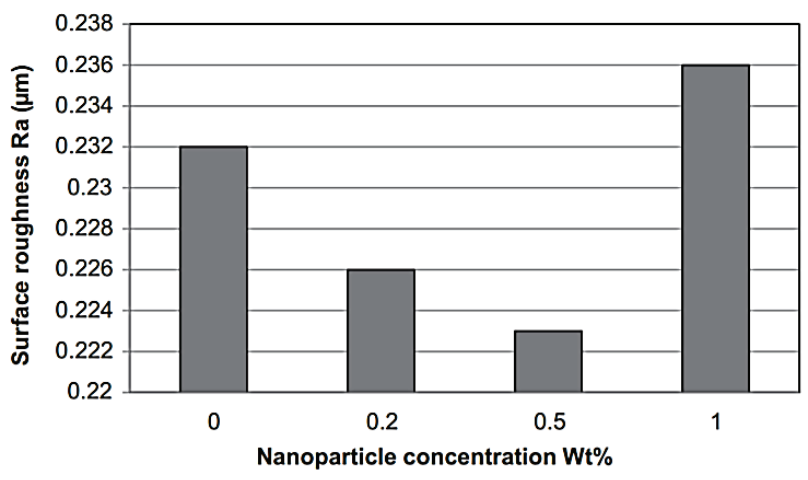

Figure 3 Surface roughness at different nanoparticle concentration [40]

Nam et al. [41] conducted experiments in drilling of the aluminum 6061 workpiece in the cases of compressed air lubrication, pure MQL and nanofluid MQL. The results indicated that MQL with the nanofluid enable reducing the drilling torques and thrust forces. Also a much larger number of drilled holes is achieved.

Previous studies presented that there was not much study about MQL milling with nanofluid. For this reason, much space is left for research in terms of the combination of nanoparticles and alternative techniques for cooling and lubrication in different machining processes. In various studies MQL technique showed as cheaper, healthier and safer than conventional CFs machining, achieving almost the same results.

In recent years, researchers have devoted more attention to the application of compressed cold air by using a vortex tube as an alternative method of cooling.

\section{COOLING PROCESS USING COMPRESSED COLD AIR BY VORTEX TUBE}

Compressed cold air, as a cutting fluid, has a good characteristic of heat dissipation in contact area tool/workpiece, tool/chips, cooling of tool and workpiece, as well as elimination of separated chips. From the effectiveness point of view, it reduces manufacturing costs, and it has no detrimental impact on the environment and human health. Cooling process with the use of compressed cold air is performed by a vortex tube, also known as Ranque-Hilsch vortex tube (RHVT), Fig. 4 [42, 43].

Vortex tube was first invented by French metallurgist and physicist Georges Ranque in 1933., and improved in the mid 1940s by German physicist Rudolf Hilsch [44, 45, 46]. The working principle of the RHVT is based on the 
separation of incoming compressed air on two streams, the hot one and the cold one. Cold air stream leaves vortex through the central orifice diaphragm next to the inlet plane. In the same time, hot stream exits vortex through control valves at the far end of the tube. From the sustainability point of view, free and clean compressed air puts this technique on the tron of the most acceptable alternative methods in machining process [47]. In the early studies compressed air of room temperature was used, which, in relation to the cooling by conventional CFs, was proved to be ineffective. Recent studies in which processing takes place with cooling with compressed cold air with the help of vortex tubes give results that are comparable to conventional CFs, and in many cases much better.

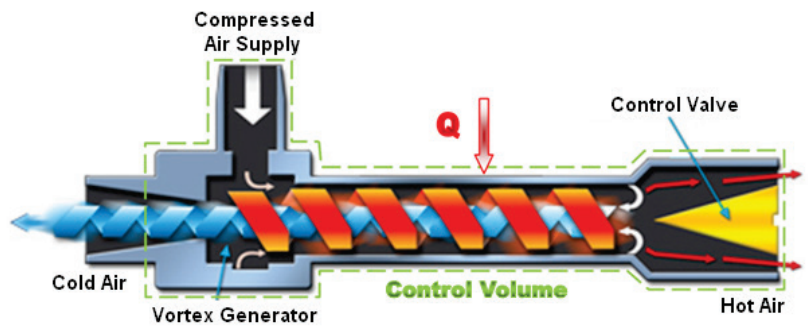

Figure 4 The Ranque-Hilsch vortex tube [42]

Aljuwayhel et al. [48] studied the performance of the vortex tube from the point of view of the temperature and velocity distributions in the vortex chamber. Sudhakar and Mihir [49] in their study have shown a series of papers which use vortex tube as a technique of cooling in the last decades, Fig. 5.

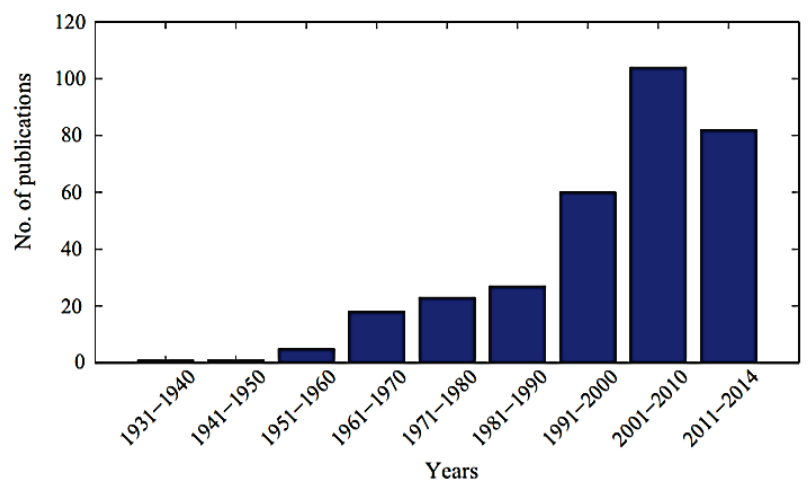

Figure $\mathbf{5}$ Number of published papers on vortex tubes by decades [49]

Boswell and Chandratilleke [50] recorded that the temperature in turning process by using RHVT was $40^{\circ} \mathrm{C}$ lower than temperature obtained during traditional $\mathrm{CFs}$ machining and $210{ }^{\circ} \mathrm{C}$ lower than temperature in dry machining. Ekinović at al. [51, 52] presented turning with compressed cold air of different workpiece materials: alloyed steel, aluminium bronze, and pure aluminium. Results of experiments indicated that the use of compressed cold air in machining process is an excellent alternative approach to improving machinability of soft materials. Liu and Chou [53] investigated machining of A390 silicon aluminum alloys during turning with the aim of reducing cutting temperatures and tool wear with compressed cold air at $-25{ }^{\circ} \mathrm{C}$ to $-15{ }^{\circ} \mathrm{C}$ generated by vortex tube. The authors concluded that the use of higher cutting speed and low feed value with the help of compressed cold air achieved reduction in temperature in the cutting zone and longer tool life. Celent et al. [54] demonstrated the capabilities and benefits of applying cooling with compressed cold air at $-2{ }^{\circ} \mathrm{C}$ by vortex tube in end milling process of steel $42 \mathrm{CrMo} 4$. In the study, the surface quality and tool life in different cutting conditions like dry machining, convencional CFs and compressed cold air cooling were analysed. The experimental results confirmed the best conditions are obtained during machining with compressed cold air.

A number of nozzles, the distance between the nozzle tip and the cutting zone, ratio of the length and diameter (L/D), air mass flow rate, air pressure, and the air temperature have a significant role concerning the output values of process during application of compressed cold air by vortex tube. Hilsch [55] stated that ratio L/D should be around 50 for good temperature separation. Westley [56] pointed out that for good temperature separation length of the tube must be 10D. Xue and Arjomandi [57] investigated the effect of the angle of rotating flow on the performance and efficiency of the RHVT. It was confirmed that angle of RHVT had an important role in both the separation of cold and hot air streams, and the vortex tube performance. Authors confirmed that the highest efficiency can be achieved when the input pressure is around 4 bars, and that a better performance of the vortex tube can be achieved at higher input pressure. Choi et al. [58] confirmed that the compressed cold air at pressure of 4 bars and temperature of $-4{ }^{\circ} \mathrm{C}$ to $-25{ }^{\circ} \mathrm{C}$ during grinding process is reducing temperature in the cutting zone, as well as increasing the surface quality and reducing residual stresses, compared to conventional CFs cooling. Nandy et al. [59] reported that increasing of tool life and productivity can be achieved during turning of Ti-6Al-4V alloy with cooling by compressed cold air. Sarma and Dixit [60] reported that at higher cutting speeds of $400 \mathrm{~m} / \mathrm{min}$ and above with cooling by compressed cold air the tool flank wear and surface finish were significantly reduced and the tool life was increased compared to dry turning.

Results incurred during the literature review suggest that the use of compressed cold air with vortex tube in machining process opens up the possibility for optimization machining processes whereby increasing efficiency of machining. It should be noted that the technique of cooling by the compressed cold air completely satisfies the social and environmental conditions of GM strategy which has a major impact on the sustainability of the economic component of the machining process.

Based on the results of research in the various machining processes by machining of different workpiece materials with various types of coated tools real opportunities are created in terms of complete leaving of conventional CFs from manufacturing industries. State of the literature clearly shows that extensive investigations have to be carried out in order to obtain more effective and environmentally friendly machining process. In this regard, a cooling technique with compressed cold air is the best alternative.

One of the main drawbacks of compressed cold air is that during machining with excellent cooling sufficient lubrication in the cutting zone is not provided. This problem presents impossibility of complete replacement of 
positive functions of the conventional CFs which are provided during machining.

Combination of compressed cold air and the minimum amount of oil in terms of MQL would present a new technique that would be an effective mean for cooling and lubrication of cutting zone. It is expected that this technique has a very small negative impact on the sustainability of the process due to the small amount of used lubricant. On the other hand, due to the particles which would be located in a stream of compressed cold air, it is expected to achieve as satisfactory or much better output values compared to conventional CFs.

\section{COOLING PROCESS USING COMPRESSED COLD AIR IN COMBINATION WITH MINIMUM QUANTITY LUBRICATION}

Compressed cold air in combination with MQL in machining processes represent an alternative to the traditional conventional machining from the viewpoint of machining costs, economic and ecological sustainability, and besides that elimination of negative impacts on the human health. Ginting et al. [61] indicated that the global warming, cumulative energy, eutrophication, and human toxicity can be avoided by $21 \%, 32 \%, 81 \%$ and $87 \%$, respectively due to replacement of the traditional cooling CFs system with the MQL system, which represents a great advantage for the combination of compressed cold air and MQL system. Boswell and Islam [62] in their study processed aluminium alloy A356 during end milling process. Experiments were carried out using five different machining conditions like dry, convencional CFs, cooled air, MQL and combination of compressed cold air with MQL. Authors point out that cold air is delivered to the cutting zone by vortex tube with pressure of 6 bars at the temperature of $-5^{\circ} \mathrm{C}$. Distance between nozzle and cutting zone was about $25 \mathrm{~mm}$. Results indicated that combination of compressed cold air with MQL has given better results with respect to all techniques except only MQL technique in terms of cutting forces, power and surface roughness, Fig. 6 and Fig. 7.

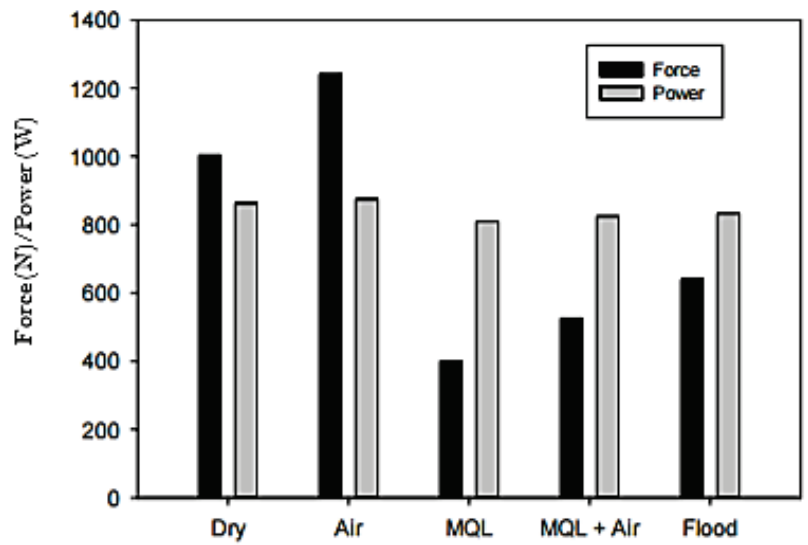

Figure 6 Cutting forces and power during milling for different machining environment [62]

Also, authors [62] confirmed that compressed cold air in combination with MQL can be used in end milling process with recommended cutting parameters and with a defined number of nozzles and their distance from the cutting zone. Zhang and Wei [63] examined machinability of medium carbon steel C45 with technique of cold compressed air in combination with MQL. Results indicated that MQL in $40 \mathrm{ml} / \mathrm{h}$, cold air temperature at -45 ${ }^{\circ} \mathrm{C}$ and feed rate of $0.2 \mathrm{~mm} / \mathrm{r}$ produces the best results in terms of tool wear and tooth/face roughness during hobbing of medium carbon steel. Experimental data show that the amount of MQL is a dominant parameter, followed by temperature of cold air and feed rate in optimization of machining. Zhang et al. [64] noted that compressed cold air at $-30{ }^{\circ} \mathrm{C}$ in combination with MQL improved tool life 1.57 times compared to dry machining during end milling. The experimental result confirmed that biodegradable vegetable oil substantially alleviates the machinability of Inconel 718 in terms of the tool life and cutting forces. Boswell and Voges [65] examined a combination of compressed cold air cooling in combination with MQL of small amounts of vegetable oil during end milling of 1040 steel. The experimental results showed that performance of this cooling system can be used to increase the tool life and cutting forces with recommended cutting parameters. Oliveria et al. [66] indicated that the use of compressed cold air stream placed at an optimal angle $30^{\circ}$ or $60^{\circ}$ in combination with MQL during grinding makes it possible to increase the specific material removal rate, reducing the grinding time without harming the workpiece quality. Deiad et al. [67] stated that the cold compressed air in combination with MQL with vegetable oil during turning of titanium Ti-6Al-4V gives the lowest flank wear of the cutting tool. It is evident that cold air has high cooling capacity and that biodegradable vegetable oil provides good lubrication of cutting zone between tool and workpiece.

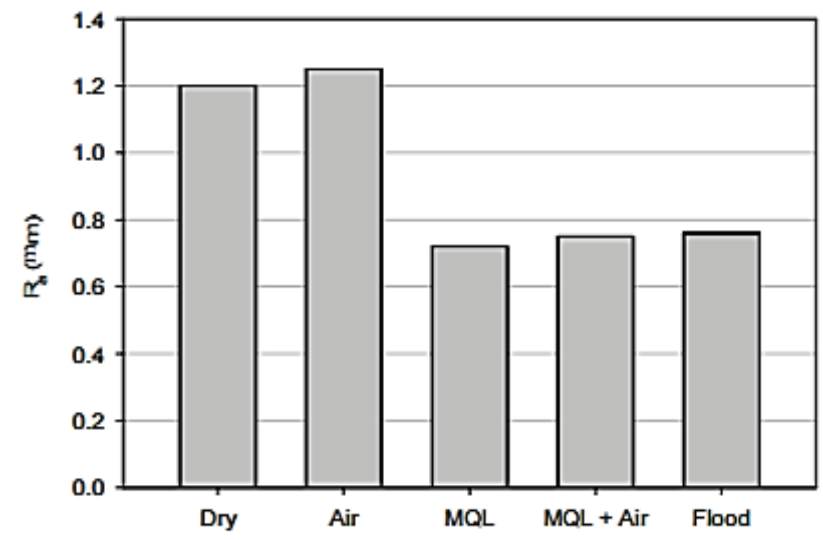

Figure 7 Surface roughness during milling for different machining environment [62]

Combination of compressed cold air and MQL can provide the low friction force at the tool/chip and tool/workpiece interface due to its superior cooling and lubrication performances. Yuan et al. [68] noted that cold compressed air at the temperature of $-15^{\circ} \mathrm{C}$ in combination with MQL increased the tool life and achieved best results of surface roughness during turning of Ti-6Al$4 \mathrm{~V}$ alloy using uncoated cutting tool. Boswell et al. [69] concluded that the effective cooling and lubrication during grinding process can be achieved by a combination of cold compressed air and MQL technique. Saberi el al. [70] confirmed that MQL technique in combination with cold 
compressed air significantly reduce tangential force and friction coefficient during grinding of soft steel materials.

Cooling technique that used cold compressed air in combination with MQL provides companies an effective environmental and ecological solution to eliminating conventional CFs. However, it is evident that this technique is not researched enough in machining processes. Thus, this technique offers the possibility of further applications in machining processes in order to comply with the results of research which can make some concrete conclusions.

During machining of different workpiece materials in combination with different cutting tools, an opportunity to create a database for monitoring output values appears. Based on the output data, clear conclusions about the effectiveness of applied technique in all segments of sustainability would be obtained.

\section{CONCLUSION}

In this paper, the application of different techniques for cooling, flushing and lubrication during the machining process with the aim of fulfilling all the segments of sustainable development of the machining process (ecological, economic and sociological) is presented.

It may be concluded that dry machining process represents the most acceptable solution in the terms of fulfilling ecological and health sustainability. However, its great disadvantage is too high temperature which is developed in the cutting zone, as well as finiteness in specific processes and for specific types of materials, especially when it comes to soft materials. The solution of this problem is seen in the application of the new materials for tool manufacturing and tool coating, what in the end results in increased total cost of machining process and brings into question the fulfilment of economic sustainability.

In that way, the application of MQL represents the alternative which would replace the lack of the dry machining process and enable the machining of the materials which exclusively demand cooling. One of the important advantages of this technique is the application of vegetable biodegradable oils, which are due to their high biodegradability and minimum negative impact to the environment, desirable in the machining process. The costs of purchasing, implementing and maintaining of MQL are listed as the greatest disadvantages, then maintenance of the system after the use. Considering temperature as the main indicator of the development of the different mechanisms of tool wear, and the number of other negative impacts which are noticed during the machining process, cooling with cold compressed air represents the alternative solution in regard to previously listed cooling, flushing and lubrication techniques.

The research has shown that the choice of the suitable conditions and cutting parameters with the use of cold compressed air results in less tool wear, better surface roughness, lower temperatures, and cutting forces in regard to the dry machining, conventional CFs and MQL technique application. Those results are especially highlighted in the case of machining materials with increased hardness. One of the basic disadvantages in most of the research is the lack of lubrication in the cutting zone.
On the other hand, ecological and social sustainability are fulfilled. In the terms of advancement of machining process by applying cold compressed air, the combination of minimal oil particles which would be injected in the stream of cold compressed air is a progress.

Technique of combination of compressed cold air and MQL is not actively used in machining processes especially in the machining of soft materials and their alloys. The literature review still has not given a clear picture of the effectiveness of this technique. Research which will be conducted in the future should be based on the appliance of MQL in a stream of compressed cold air with the help of the vortex tube so their efficiency could be observed in various conditions of the machining process.

It is assumed that this technique will increase the efficiency of cooling with compressed cold air by using vortex tube, and that MQL in a stream of compresed cold air will provide enough cooling and lubrication of the cutting zone in order to increase productivity and quality of final products and to ensure a longer cutting tool life.

Also, it would be clear to see the possibility of further improvement of the technique, with its advantages and disadvantages in order to meet requirements of sustainable machining.

\section{REFERENCES}

[1] Krajnc, D. \& Glavič, P. (2003). Indicators of sustainable production. Clean Techn Environ Policy, 5, 279-288. https://doi.org/10.1007/s10098-003-0221-z

[2] Dixit, U. S., Sarma, D. K., \& Davim, P. J. (2012). Environmentally Friendly Machining. Springer Briefs in Applied Sciences and Technology. https://doi.org/10.1007/978-1-4614-2308-9

[3] Yildiz, Y. \& Nalbant, M. (2008), A review of cryogenic cooling in machining processes. International Journal of Machine Tools \& Manufacture, 48, 947-964. https://doi.org/10.1016/j.jimachtools.2008.01.008

[4] Glenn, F. T. \& Van, A. (2004). Opportunities and Market Trend in Metalworking Fluids. Journal of the Society of Tribologists and Lubrication Engineers, 54, 31-34.

[5] Brockhoff, T. \& Human Services. (1983). https://cfpub.epa.gov/si/si_public_record_Report.cfm?dirEn tryID $=132500(27.11 .2016)$

[6] (1983). National Occupational Exposure Survey (NOES). US Department of Health and Human Services, Cincinnati, $\mathrm{OH}$.

[7] Taia, B. L., Stephenson, D. A., Furnessb, R. J., \& Shiha, A. J. (2014). Minimum Quantity Lubrication (MQL) in Automotive Powertrain Machining. Procedia CIRP, 14, 523528. https://doi.org/10.1016/j.procir.2014.03.044

[8] Koné, F., Czarnota, C., Haddag, B., \& Nouari, M. (2013). Modeling of velocity-dependent chip flow angle and experimental analysis when machining 304L austenitic stainless steel with groove coated-carbide tools. Journal of Materials Processing Technology, 213, 1166-1178. https://doi.org/10.1016/j.jmatprotec.2013.01.015

[9] Pusavec, F., Kramar, D., Krajnik, P., \& Kopac, J. (2010). Transitioning to sustainable production - part II: evaluation of sustainable machining technologies. J. Clean. Prod., 18, 1211-1221. https://doi.org/10.1016/j.jclepro.2010.01.015

[10] Watts, D. (2012). Sustainable Metalworking with Minimum Quantity Lubrication, Production Machining. http://www.productionmachining.com/articles/sustainablemetalworking-with-minimum-quantity-lubrication 
[11] US Environmental Protection Agency. (2008). Climate Protection Partnerships Division and Municipal Support Division, USA.

[12] The Dow Chemical Company. (2011). A Different Look at Water: Part I, USA.

[13] European Comission. (2006). EU REACH Directive, Environment Directorate General.

[14] Sreejith, P. S. \& Ngoi, B. K. A. (2000). Dry machining: Machining of the future. Journal of Materials Processing Technology, 101, 287-291. https://doi.org/10.1016/S0924-0136(00)00445-3

[15] Mitsbubischi material corporation. Cutting tool materials, http://www.mitsubishicarbide.net/contents/mmus/enus/html /product/technical_information/information/sessaku.html

[16] Tönsholf, H. K. \& Mohflfeld, A. (1997). PVD - Coatings for wear protection in dry cutting operations. Surface and Coatings Technology, 93, 88-92. https://doi.org/10.1016/S0257-8972(97)00027-3

[17] Weinert, K., Inasaki, I., Sutherland, J. W., \& Wakabayashi, T. (2004). Dry Machining and Minimum Quantity Lubrication. CIRP - Anals, Manufacturing Technology, 53, 511-537

[18] Ozcelik, B., Kuram, E., \& Simsek, B. T. (2011). Comparison of dry and wet end milling of AISI 316 stainless steel. Mater Manuf Processes, 26, 1041-1049. https://doi.org/10.1080/10426914.2010.515645

[19] Kuram, E., Ozcelik, B., \& Demirbas, E. (2013). Environmentally Friendly Machining: Vegetable Based Cutting Fluids. Green Manufacturing Processes and Systems, Springer, 23-47.

[20] Gökkaya, H. (2010). The Effects of Machining Parameters on Cutting Forces, Surface Roughness, Built-Up Edge (BUE) and Built-Up Layer (BUL) During Machining AA2014 (T4) Alloy. Journal of Mechanical Engineering, $56,584-593$

[21] Autret, R. \& Liang, S. Y. (2003). Minimum quantity lubrication in finish hard turning. Proc. International Conference on Humanoid, 1-9.

[22] Tschätsch, H. \& Reichelt, A. (2009). Cutting Fluids (Coolants and Lubricants). Applied Machining Technology. Springer, Berlin Heidelberg. https://doi.org/10.1007/978-3-642-01007-1

[23] Sharma, V. S., Dogra, M., Suri, N. M. (2009). Cooling techniques for improved productivity in turning. International Journal of Machine Tools \& Manufacture, 49, 435-453. https://doi.org/10.1016/j.jimachtools.2008.12.010

[24] Treurnicht, N. F., Joubert, H. J., Oosthuizen, G. A., \& Akdogan, G. (2010). Investigating of Eco- and Energyefficient Lubrication Strategies for the Drilling of Light Metal Alloys. South African Journal of Industrial Engineering, 21, 25-38

[25] Murthy, K. S. \& Rajendran, I. (2010). A study on optimisation of cutting parameters and prediction of surface roughness in end milling of aluminium under MQL machining. Int. J. Machining and Machinability of Materials, 7, 112-128 https://doi.org/10.1504/IJMMM.2010.029849

[26] Deutsche Gesetzliche Unfallversicherung DGUV. Minimum quantity lubrication for machining operations, Berlin, 2010.

[27] Zeilmann, R. P. \& Weingaertner, W. L. (2006). Analysis of temperature during drilling of Ti-6Al-4V with minimal quantity of lubrication. J. Mater. Process. Technol., 179, 124-127. https://doi.org/10.1016/j.jmatprotec.2006.03.077

[28] Heisel, U., Lutz, S. M., Spath, D., Wassmer, R., \& Ulrich, W. (1994). Application of Minimum Quantity Cooling Lubrication Technology in Cutting Processes. Production Engineering, 2, 49-54.

[29] Shahrom, M. S., Yahya, N. M., \& Yusoff, A. R. (2013). Taguchi method approach on effect of lubrication condition on surface roughness in milling operation. Procedia Engineering, 53, 594-599. https://doi.org/10.1016/i.proeng.2013.02.076

[30] Wakabayashi, T., Inasaki, I., \& Suda, S. (2007). Tribological action and optimal performance: Research activities regarding $M Q L$ machining fluids Machining Science and Technology. Taylor \& Francis, 59-85.

[31] Nurul, A. M. J., Kamaleshwaran, T., Ahamd F. M., \& Azwan I. A. (2014). A Study of Surface Roughness \& Surface Integrity in Drilling Process Using Various Vegetable - Oil Based Lubricants In Minimum Quantity Lubrication. Australian Journal of Basic and Applied Sciences, 8, 191197.

[32] Tazehkandi, A. H., Shabgard, M., Pilehvarian, F. (2015). On the feasibility of a reduction in cutting fluid consumption via spray of biodegradable vegetable oil with compressed air in machining Inconel 706. Journal of Cleaner Production, 104, 422-435. https://doi.org/10.1016/j.jclepro.2015.05.039

[33] Sharma, J. \& Sidhu, B. S. (2014). Investigation of effects of dry and near dry machining on AISI D2 steel using vegetable oil. Journal of Cleaner Production, 66, 619-623. https://doi.org/10.1016/j.jclepro.2013.11.042

[34] Khan M. M. A., Mithu, M. A. H., \& Dhar, N. R. (2009) Effects of minimum quantity lubrication on turning AISI 9310 alloy steel using vegetable oil-based cutting fluid. Journal of Materials Processing Technology, 209, 55735583. https://doi.org/10.1016/j.jmatprotec.2009.05.014

[35] Liao, Y. S., Lin, H. M., \& Chen, Y. C. (2007). Feasibility study of the minimum quantity lubrication in high-speed end milling of NAK80 hardened steel by coated carbide tool. International Journal of Machine Tools and Manufacture, 47, 1667-1676. https://doi.org/10.1016/.ijmachtools.2007.01.005

[36] Alper, U., Furkan, D., \& Erhan, A. (2015). Applying Minimum Quantity Lubrication (MQL) Method on Milling of Martensitic Stainless Steel by Using Nano MoS2 Reinforced Vegetable Cutting Fluid. Procedia - Social and Behavioral Sciences, 195, 2742-2747. https://doi.org/10.1016/i.sbspro.2015.06.384

[37] Subhash, P. C. B., Rao, C. S. P., \& Jawale, K. (2014). Role of MQL and Nano Fluids on the Machining of Nicrofer C263. All India Manufacturing Technology, Design and Research Conference / Assam, India, 1-5.

[38] Rahmati, B., Sarhan, A. A. D., \& Sayuti, M. (2013). Investigating the optimum molybdenum disulfide (MoS2) nanolubrication parameters in CNC milling of AL6061-T6 alloy. Int. J Adv Manuf. Technol., 70, 1143-1155. https://doi.org/10.1007/s00170-013-5334-x

[39] Sayuti, M., Ahmed, A., Sarhan, D., \& Hamdi, M. (2012). An investigation of optimum $\mathrm{SiO} 2$ nanolubrication parameters in end milling of aerospace Al6061-T6 alloy. Int $J A d v$ Manuf Technol, 67, 833-849. https://doi.org/10.1007/s00170-012-4527-z

[40] Rahmati, B., Sarhan, A., Sayuti, M. (2014). Morphology of surface generated by end milling AL6061-T6 using molybdenum disulfide (MoS2) nanolubrication in end milling machining. Journal of Cleaner Production, 66, 685691. https://doi.org/10.1016/j.jclepro.2013.10.048

[41] Nam, J. S., Lee, P. H., \& Lee, S. W. (2011). Experimental characterization of micro-drilling process using nanofluid minimum quantity lubrication. International Journal of Machine Tools and Manufacture, 51, 649-652. https://doi.org/10.1016/j.jimachtools.2011.04.005

[42] Byrne, G., Dornfeld, D., \& Denkena, B. (2003)Advanced Cutting Technology. CIRP / Annals, 52, 483-507. https://doi.org/10.1016/S0007-8506(07)60200-5

[43] Upendra, S. G., Manoj, K. J., \& Saurabh, R. (2013). Thermodynamic Analysis of Counter Flow Vortex Tube. International Journal of Engineering Research \& Technology, 2, 1-10. 
[44] Ranque, G. J. (1934). Method and Apparatus for Obtaining from a Fluid under Pressure Two Outputs of Fluid at Different Temperatures. US patent no. 1:952,281.

[45] Ranque, G. J. (1933). Experiments on expansion in a vortex with simultaneous exhaust of hot air and cold air. $J$ Phys Radium, 4, 112-114.

[46] Hilsch, R. (1947). The use of the expansion of gases in a centrifugal field as cooling process. Review of Scientific Instruments, 18, 108-113. https://doi.org/10.1063/1.1740893

[47] De Vera, G. The Ranque-Hilsch Vortex Tube, (2010). $\mathrm{http}: / /$ docplayer.net/26185420-The-ranque-hilsch-vortextube.html (2.12.2016)

[48] Aljuwayhel, N. F., Nellis, G. F., \& Klein, S. A. (2005). Parametric and internal study of the vortex tube using a CFD model. Renewable and Sustainable Energy Reviews, 28, 172-178. https://doi.org/10.1016/j.jirefrig.2004.04.004

[49] Sudhakar, S. \& Mihir, S. (2015). Review of Ranque-Hilsch vortex tube experiments using air. Renewable and Sustainable Energy Reviews, 52, 172-178. https://doi.org/10.1016/j.rser.2015.07.103

[50] Boswell, B., Chandratilleke, T. T. (2009). Air-Cooling Used for Metal Cutting. American Journal of Applied Sciences, 6, 251-262. https://doi.org/10.3844/ajassp.2009.251.262

[51] Ekinović, S., Begović, E., Fakić, B., Burić, A., \& Čeliković, A. (2014). Cold air dry machining Part 1: Experimental setup. Journal of Trends in the Development of Machinery and Associated Technology, 18, 39-42.

[52] Ekinović, S., Begović, E., Fakić, B., Burić, A., \& Čeliković, A. (2014). Cold air dry machining Part 2: SEM and Metallographic analysis of the chip. Journal of Trends in the Development of Machinery and Associated Technology, 18, 43-46.

[53] Liu, J. \& Chou, K. (2007). On temperatures and tool wear in machining hypereutectic Al-Si alloys with vortex-tube cooling. Machine Tools \& Manufacture, 47, 635-645. https://doi.org/10.1016/j.jimachtools.2006.04.008

[54] Celent, L., Bajić, D., \& Jozić, S. (2013). Effect of cooling with cold compressed air using vortex tube on tool performance in milling process. Computer integrated manufacturing and high speed machining / Zagreb, 87-92.

[55] Hilsch, R. (1947). The use of the expansion of gases in a centrifugal field as cooling process. Review of Scientific Instruments, 18, 108-113. https://doi.org/10.1063/1.1740893

[56] Westley, R. (1957). Vortex tube performance data sheets. College of Aeronautics, Cranfield College.

[57] Xue, Y. \& Arjomandi, M. (2008). The effect of vortex angle on the efficiency of the Ranque-Hilsch vortex tube. Experimental Thermal and Fluid Science, 33, 54-57. https://doi.org/10.1016/j.expthermflusci.2008.07.001

[58] Choi, H. Z., Lee, S. W., \& Jeong, H. D. (2002). The cooling effects of compresed cold air in cylindrical grinding with alumina and CBN wheels. Journal of Materials Processing Technology, 127, 155-158. https://doi.org/10.1016/S0924-0136(02)00117-6

[59] Nandy, A. K., Gowrishankar, M. C., \& Paul, S. (2009). Some studies on high-pressure cooling in turning of $\mathrm{Ti}-6 \mathrm{Al}-4 \mathrm{~V}$. International Journal of Machine Tools Mannufacturing, 49, 182-198. https://doi.org/10.1016/j.jmachtools.2008.08.008

[60] Sarma, D. K. \& Dixit, U. S. (2007). A comparision of dry and air-cooled turning of grey cast iron with mixed oxide ceramic tool. Journal of Materials Processing Technology, 190, 160-171. https://doi.org/10.1016/j.jmatprotec.2007.02.049

[61] Gintinga, R. Y., Boswell, B., Biswas, W., \& Islam, N. (2015). Advancing Environmentally Conscious Machining. $12^{\text {th }}$ Global Conference on Sustainable Manufacturing / Procedia CIRP 26, 391-396.

[62] Boswell, B. \& Islam, M. N. (2012). Feasibility Study of Adopting Minimal Quantities of Lubrication for End Milling Aluminium. Proceedings of the World Congress on Engineering / London.
[63] Zhang, G. \& Wei, H. (2010). Selection of optimal process parameters for gear hobbing under cold air minimum quantity lubrication cutting environment. Proceedings of the $36^{\text {th }}$ International Matador Conference / London, 231-234. https://doi.org/10.1007/978-1-84996-432-6_53

[64] Zhang, S., Li, J. F., \& Wang, Y. W. (2012). Tool life and cutting forces in end milling inconel 718 under dry and minimum quantity cooling lubrication cutting conditions. Journal of Cleaner Production, 32, 81-87. https://doi.org/10.1016/j.jclepro.2012.03.014

[65] Boswell, B. \& Voges, E. (2012). The Effect of Combined Cold Air and Minimum Liquid Cooling on End Milling. Advances in Mechanical Engineering, 2, 1-7.

[66] Oliveira, D. J., Guermandia, L. G., Bianchia, E. C., Dinizb, A. E., Aguiarc, P. R., \& Canarim, R. C. (2012). Improving minimum quantity lubrication in $\mathrm{CBN}$ grinding using compressed air wheel cleaning. Journal of Materials Processing Technology, 212, 2559-2568. https://doi.org/10.1016/j.jmatprotec.2012.05.019

[67] Deiab, I., Raza, S. W., \& Pervaiz, S. (2014). Analysis of Lubrication Strategies for Sustainable Machining during Turning of Titanium Ti-6Al-4V alloy. Procedia CIRP 17, 766-771. https://doi.org/10.1016/j.procir.2014.01.112

[68] Yuan, S. M., Yan, L.T., Liu, W.D., \& Liu, Q. (2011). Effects of cooling air temperature on cryogenic machining of Ti6Al-4V alloy. Journal of Materials Processing Technology, 211, 356-362. https://doi.org/10.1016/j.jmatprotec.2010.10.009

[69] Boswell, B., Ginting, Y. R., Biswas, W. K., \& Islam, M. N. (2016). Environmental Generation of Cold Air for Machining. The $13^{\text {th }}$ Global Conference on Sustainable Manufacturing / Procedia CIRP 40, 648-652.

[70] Saberi, A., Rahimi, A. R., Parsa, H., Ashrafijou, M., \& Rabiei, F. (2016). Improvement of surface grinding process performance of CK45 soft steel by minimum quantity lubrication (MQL) technique using compressed cold air jet from vortex tube. Journal of Cleaner Production, 131, 728738. https://doi.org/10.1016/j.jclepro.2016.04.104

\section{Contact information}

Mario DRAGIČEVIĆ, Mag. Ing. Mech., Assistant

Faculty of Mechanical Engineering, Computing and Eletrical Engineering, University of Mostar

Matice hrvatske bb, 88000 Mostar, Bosnia and Herzegovina

E-mail: mario.dragicevic@sve-mo.ba 